\title{
WACQUEZ Y SUS PRECURSORES: INFANCIA, GÉNERO Y NACIÓN ${ }^{1}$
}

\author{
Lorena Amaro Castro \\ Instituto de Estética, Pontificia Universidad Católica de Chile \\ lamaro@uc.cl
}

RESUMEN / ABSTRACT

La novela Epifanía de una sombra (2000), de Mauricio Wacquez, es el punto de partida para una relectura de dos conocidos intelectuales chilenos: Benjamín Subercaseaux y Luis Oyarzún. Como ellos, Wacquez representa la infancia como espacio de descubrimiento existencial y posible perspectiva crítica del tramado familiar. Junto a los pequeños protagonistas de Daniel. Niño de lluvia (1938), de Subercaseaux, y La infancia (1940) y Los días ocultos (1955), de Oyarzún, Santiago, personaje principal de Epifanía, indica un modo de leer la formación de la masculinidad a lo largo de la primera mitad del siglo XX en Chile, proponiendo imaginarios estéticos y genérico-sexuales subversivos respecto de los discursos normalizadores erigidos por las instituciones políticas y sociales.

Palabras Clave: masculinidades, infancia, novela chilena, homoerotismo, nación.

The novel Epifanía de una sombra (2000), by Mauricio Wacquez, constitutes a starting point for a new reading of two well-known Chilean intellectuals: BenjaminSubercaseaux and Luis Oyarzún. Just like these latter, Wacquez represents the childhood as a space of existential discovery and possibly, a critical perspective of the family scheme. Similarly to the young characters of Daniel. Niño de lluvia (1938), by Subercaseaux, and La infancia (1940) y Los días ocultos (1955), by Oyarzún, Santiago, the main character of Epifanía, offers a way of reading the formation of masculinity during the first half of the XXth Century in Chile, by

1 Este artículo presenta los resultados obtenidos en el proyecto FONDECYT Regular 1120654, "Fronteras de infancia, género y nación en diez novelas autobiográficas chilenas", en que participo como investigadora responsable. Agradezco a Francisca Lange y Ghislaine Arecheta, coinvestigadoras del proyecto, su lectura y observaciones a este texto. 
proposing subversive aesthetic and gender/sexual imaginations that differ from the normalizing discourses constructed by political and social institutions.

KEY WORDS: Masculinities, Childhood, Chilean novel, Homoeroticism, Nation.

El siguiente artículo es producto de un ejercicio crítico: pensar la literatura chilena del siglo XX a partir de la idea borgeana de los "precursores"; esto es, inventar una trayectoria, un recorrido, una retorcida "tradición", remontarse a posibles precursores que quizás nada tendrían que ver entre ellos, de no ser por un eventual epígono, aquel punto final hacia el cual convergen lecturas muy disímiles, las que aparecen como marcas, como huellas de una historia invisible... pero posible. En este caso, cierta producción del escritor colchagüino Mauricio Wacquez (1939-2000), su novela autobiográfica Epifanía de una sombra (2000), primera parte de una magna trilogía inconclusa que el autor deseaba llamar La oscuridad, dialoga con relatos de otros dos autores chilenos, textos que a mi modo de ver han sido invisibilizados, con escasas excepciones, por la crítica. Los autores son el antropólogo Benjamín Subercaseaux (1902-1973) y Luis Oyarzún (1920-1972), el conocido filósofo, académico y diarista. Las obras "precursoras", Daniel, niño de lluvia (1938), libro que tuvo varias reediciones hasta 1973, cuando se publica con el título Niño de lluvia, y de Oyarzún dos novelas muy tempranas: La infancia (1940) y Los días ocultos (1955).

"Cada escritor crea sus precursores", escribe Borges. De este modo -y esto es lo que nos concierne- modifica no solo la concepción del pasado, sino la del futuro, esto es, la proyección de estas relaciones en la lectura y, eventualmente, cabría añadir que en la formación de un canon. Procuraré analizar las cuatro novelas mencionadas teniendo en perspectiva esta posibilidad: hacer una relectura del canon literario chileno del siglo XX (al que pertenecen otras obras de Oyarzún y Subercaseaux, pero no las aquí abordadas), sobre todo desde la perspectiva de género y la construcción de las masculinidades en las representaciones novelísticas.

Si se las considera entre otros textos de los mismos autores, las novelas seleccionadas para este análisis pueden parecer secundarias, pero esa minimización -sorprende el silencio de la crítica en torno a ellas- no resulta sorprendente, toda vez que se trata de textos en cierto modo perturbadores: presentan escenas de la familia y el desarrollo de la sexualidad infantil que ciertamente debieron ser incómodos en su tiempo; no es otra cosa que "el pudor de la historia", del que habla Daniel Balderston, silencio con que fueron encubiertas durante muchas décadas las disidencias sexuales en la 
literatura continental (Sexualidades 26), silencio que pone de manifiesto, a juicio del mismo crítico, los prejuicios con que se forjan los cánones literarios (Cicatriz 27). Otro tanto ocurre con ese otro relato que hemos llamado nación, construcción imaginaria que pretende forjar identidades colectivas en un gran rompecabezas donde no calzan conductas e identidades no hegemónicas.

\section{PERSONAJES DE NOVELA}

Aunque fueron contemporáneos, Oyarzún y Subercaseaux no se vincularon como compañeros de cenáculo. Sí se encontraron, y sobre este encuentro escribe Hernán Valdés en sus memorias, Fantasmas literarios. Según él, Luis Oyarzún condenaba en el "psicoantropólogo" su charlatanería: "Lucho me dirá más tarde que sus fundamentos científicos son irrisorios, que asistió durante unos meses a unos cursos de psicología en la Sorbonne y pretende con eso haber obtenido un doctorado" (142). Wacquez los reúne en su Epifanía..., entrecruzando allí los referentes extratextuales de su escritura con la ficción. La figura de Luis Oyarzún aparece camuflada bajo el nombre "Diógenes", personaje clave en la formación filosófica y existencial del protagonista, el niño/joven Santiago de Warni, así como fue fundamental la figura tutelar de Oyarzún para la generación del 50 y la del propio Wacquez, algo más joven. Más breve, casi invisible en su dilatado relato, es la alusión a Subercaseaux, quien, a diferencia del filósofo, aparece sin disimulo, con su nombre y apellido; la encontramos recién en la página 276 , donde se elucubra sobre una posible relación de pupilaje entre el protagonista y el novelista Benjamín Subercaseaux. "Comenzar por la respetabilidad", se dice Santiago a sí mismo, insinuando que la filiación con este escritor respetable augurará el éxito en el camino literario. Acto seguido, sin embargo, añade: "se presentaría en casa del novelista tal como el alumno Dargelos lo hizo con Jean Cocteau" (ibíd.). Aparece aquí otra clave de lectura: el narrador está hablando del Libro blanco, texto de Cocteau que pretende ser un informe sobre la homosexualidad y en que Dargelos, un personaje importante de la iniciación homosexual que aparece en distintos textos del autor francés, se erige como imagen de idealidad masculina.

Es sabido que tanto Wacquez como Subercaseaux y Oyarzún eran homosexuales; pero el hilo que deseo seguir va más allá de esta coincidencia, que por cierto hace eco en la escritura de los tres. En estos relatos se cuestiona unánimemente la masculinidad hegemónica, planteando discursos alternativos en 
que la infancia y la enfermedad socavan y justifican las exploraciones sexuales de sus protagonistas y ponen en tela de juicio la dimensión institucional, escolar y familiar de la pedagogía sexual. Leídas en su conjunto, estas novelas permitirían trazar una línea de crítica social y política muy poco conocida de nuestra historia literaria, así como también una imagen de nación que, como sugiere Ignacio Álvarez al leer otras novelas chilenas, aparece entre líneas, en una "lectura intersticial, una interpretación in absentia" (33).

Una última cuestión que encadena el texto de Wacquez al de sus "precursores" es el hecho de que las cuatro novelas hayan sido consideradas "autobiográficas". El ocultamiento del nombre propio y la utilización de la ficción parecen resguardar historias y conflictos demasiado elocuentes para su tiempo, principalmente en los dos primeros autores. Es así como estos relatos entregan una serie de pistas al lector sobre su anclaje referencial, pero eluden o esconden las identificaciones a las que obliga el uso del nombre propio, lo cual permite hablar de novelas autobiográficas, pero no de autobiografías propiamente tales. En este sentido se trata de textos controvertidos. Pedro Lira Urquieta, por ejemplo, da por sentada una lectura referencial de la primera novela del filósofo Luis Oyarzún, en el discurso que da con motivo de la incorporación de éste a la Academia de la Lengua. Se refiere a La infancia como un "relato emocionado de su infancia" (cit. en Hozven 33). Por otra parte, Los días ocultos ha sido leída como una "reescritura" de La infancia (tanto por Leonidas Morales como por Roberto Hozven), en la medida en que revisita algunas líneas argumentales, sobre todo las referentes a la madre; de ser considerada esta semejanza entre los textos, bien se podría proyectar -y siguiendo el discurso de Lira Urquieta- que Los días ocultos es también escritura autobiográfica. En el caso de Subercaseaux, él mismo plantea la cuestión en el prólogo a la segunda edición:

Ahora, en este libro donde casi no aparecen nombres ni lugares, escrito en la manera confusa en que yo lo viví o como se lo vi vivir a tantos otros niños, tendré (...) que hacer (...) el papel de mentiroso; en este caso, frente a otros adultos. Mentiroso, porque mi infancia no fue la de Daniel; y a la vez, sincero, porque mi infancia la sentí así, y tanto, que hay momentos en que la suya llega a identificarse con la mía (1942, 14-15, en cursiva en el texto).

En lo que respecta a Wacquez, Brian Dendle sostiene que el escritor se refería a su proyecto en términos autobiográficos, si bien hay que decir que la novela siempre juega en ese borde inexacto de ficción y referencialidad, partiendo, 
como se ha dicho, por el enmascaramiento de los personajes y el disfraz de los nombres propios ${ }^{2}$.

Por último, es remarcable que tanto Subercaseaux como Oyarzún volvieran sobre sus relatos y los reescribieran. Cuatro ediciones tuvo el Niño de lluvia en vida del autor. Como se ha dicho, La infancia también pasó por una revisión, la que resultó en la publicación, quince años después, de un libro con un título igualmente significativo en términos de este análisis: Los dias ocultos ${ }^{3}$. Wacquez, en tanto, pareciera reescribir en un extenso relato la historia de los que he llamado sus precursores. Él revela la cara oculta, elusiva, de los textos anteriores, en que se critica el orden familiar, el patriarcado y el régimen de la hacienda, y destruye con ferocidad la concepción de la infancia como tiempo y espacio de la felicidad inocente. Los tres autores muestran una infancia enferma, acosada por fantasmas, pero es por esa misma pertenencia a lo que Susan Sontag llamó "el mundo de la enfermedad", que los pequeños protagonistas gozan $-\mathrm{y}$ he aquí la propuesta más desestabilizadora de estos autores- de ciertas libertades.

\section{LA INFANCIA DEL MUTANTE}

No toda la literatura que representa la infancia corre el mismo curso que estos textos en nuestro país. A fines del siglo XIX, la experiencia infantil es apenas consignada por los memorialistas, principalmente varones pertenecientes a la oligarquía, que buscan dar explicación a su mérito público, omitiendo de este modo los aspectos más subjetivos e íntimos de su formación. En otro polo, autores como Edwards Bello o Baldomero Lillo dan forma casi documentalmente a una infancia expoliada y marginal, la que protagonizó lo que el ensayista Ismael Valdés Valdés llamó a comienzos del siglo XX “el problema de la infancia", dando forma a lo que el historiador Jorge Rojas ve como una "tendencia predominante en la literatura del siglo XX" en Chile, la de "incorporar la figura del niño pobre en los relatos, aunque principalmente

2 El caso de Benjamín Subercaseaux, proveniente de una acaudalada familia y un medio social en que primaban las constricciones sociales, de clase, es el que parece más conflictivo. Él escribió dos prólogos, en 1938 y 1942, donde juega con la idea de que el texto es ficcional/referencial. Finalmente omite esos prólogos, en la edición de 1972, la última que se hizo en vida del autor.

A esta "reescritura" me refiero con más detalle en el artículo "La reescritura de $L a$ infancia en Los días ocultos, de Luis Oyarzún”. Revista Aisthesis n54, dic. 2013, en prensa. 
urbano, ubicándolo entre la calle y el conventillo" (288). Con posterioridad a estos autores, en las décadas entre 1930 y 1950, Oscar Castro, Nicomedes Guzmán, Carlos Sepúlveda Leyton y Manuel Rojas narraron desde experiencias más cercanas a esa realidad las precarias historias de infancia del huacherío popular, proletario. Pero recién alrededor de 1940 se dio curso a formas de narración de la niñez más intimistas por parte de los escritores provenientes de la élite social. Oyarzún y Subercaseaux, de formación universitaria e indudablemente letrados, hicieron el ademán de una revuelta desde dentro mismo de esas élites sociales e intelectuales, criticando, de manera muy subrepticia, las imposiciones hegemónicas de su clase. Después de ellos, narradores como José Donoso y Cristián Huneeus, entre 1970 y 1985, profundizarían con maestría en los códigos y desarrollarán más explícitamente los conflictos que anudan el tema de la clase social y la conducta sexual en Chile. Wacquez fue rotundo instalado ya en el siglo XXI, volviendo sobre el tema de la hacienda, nunca resuelto del todo en el universo simbólico chileno. Es precisamente ese tratamiento contemporáneo que da Wacquez al tema de la homosexualidad, su retórica sin tapujos, la que permite descubrir esos otros textos velados hasta hoy, si bien ellos exhiben las marcas de una masculinidad que se piensa y se mira a sí misma y que al mismo tiempo piensa y mira con ojo crítico la construcción de la masculinidad hegemónica. En este sentido, Bertold Schoene-Harwood plantea que "en el patriarcado la reticencia y el silencio masculinos constituyen imperativos insidiosos que protegen y controlan su autenticidad masculina. El que un hombre hable de su género de forma autoconsciente y crítica ya es indicativo de su fracaso para vivir el ideal patriarcal y de que, en consecuencia, su masculinidad está 'en problemas"' (Schoene-Harwood viii, la cursiva es mía). Empleando diversos recursos (los que cada uno encuentra disponibles en su época), estos autores construyen escenas en que se habla de la masculinidad, tema habitualmente postergado o silenciado por los autobiógrafos de la época, quizás porque no tienen nada que agregar a lo que desde la sociedad se les impone decir.

En Daniel... encontramos el relato de un adulto que rememora las experiencias del protagonista desde su más temprana edad hasta su adolescencia. Daniel es lo que el narrador denominará, a lo largo de toda su relato, un "niño de lluvia", categoría que define en su oposición a la de "niños de sol"4, que

$4 \quad$ A esta oposición nos hemos referido también con GhislaineArecheta en el artículo "Modernización y experiencias de infancia en la narrativa chilena de la primera mitad del siglo 
parece encarnar la masculinidad hegemónica de principios del siglo XX en América Latina:

Si a veces su mirada parece tornarse sombría y su carácter retraído, no es por culpa de ellos: los niños de lluvia podrían ser los más felices de la tierra si estuvieran solos en el mundo; pero hay los otros, los de sol. Estos no viven así, pacíficamente; se desarrollan con ferocidad; tienen hambre de conquista y de superación brutal. No es mucho lo que avanzan en la vida, pero sí mucho lo que destruyen y hieren en su afán de avanzar. Los niños de lluvia [...] no les temen ni son tímidos, como lo han creído los psicólogos de profesión. Se saben mejores, pero son demasiado conscientes para decidirse a competir en una lucha así. Además, hay en los niños de lluvia como una derrota anticipada: su propia sensibilidad (1973, 116 - 117).

"Hambre de conquista" y de "superación brutal" encarnan el ideal guerrero que hacia 1910 -época en que se ambienta este relato- persistía en Chile, en medio de una gran crisis moral y social. Alimentaban este ideario los recuerdos y figuraciones de la Guerra del Pacífico (1879-1883) y la Guerra contra la Confederación Perú-Boliviana (1836-1839), además del conflicto, más reciente, de la Guerra Civil del 91 . El afán conquistador del varón atraviesa las clases sociales, encontrando expresiones muy claras en el baile nacional, "la cueca", como también en las festividades y manifestaciones populares. De esta cultura machista y desgarradora da cuenta, asimismo, el ensayo "Menos cóndor y más huemul", de Gabriela Mistral, publicado en 1925.

Daniel se enfrenta, pues, con la agresividad de los niños de sol desde el comienzo de la novela, cuando se relata uno de sus primeros cumpleaños, al que la familia tiene la mala idea de invitar amiguitos que, por cierto, el niño no conoce. Es así como se topa "con los demás" (entre comillas en el texto, 1973, 27): "Como perros que se observan por primera vez, giraron los niños en torno de Daniel mirándolo como si fuera un fenómeno. Uno de ellos, después de haber lanzado a 1os otros una mirada de connivencia, se adelantó y cogiéndolo rudamente por los rizos, le lanzó a quemarropa: 'Y éstos, por qué te los dejan tan largos..." (28). En su soledad, el niño de lluvia siente que las palabras de sus invitados hieren "como cuchillos" y, sin embargo, él

XX”, Confluencia, Volume 29 No 2 (Spring 2014), en preparación. En ese ensayo aludimos más brevemente a un número mayor de textos, procurando caracterizar las diversas narraciones de infancia surgidas en el período. 
"nunca había dado de cuchilladas a nadie" (29). La escena llega a un punto cúlmine cuando el líder del hostigamiento le pregunta con aparente cariño si tiene papá. "No... - contestó Daniel, desorientado por tanta solicitud". El niño se mofa de él: “¡Ah, apesta... no tiene ni papá!” (30). La situación de Daniel es atípica entre los pequeños de su condición social, resulta un símil del guacho popular. Pero la carencia de padre tiene además otros alcances: un niño sin padre es un niño criado por mujeres. Daniel toma conciencia de esta identidad, de este "afeminamiento" que vienen a subrayar los bucles, y por eso más adelante solicitará que se los corten, de manera de poder integrarse sin nuevas escenas traumáticas al mundo escolar. En este sentido, parece también bastante intencionado el diálogo que sostiene con la abuela paterna, cuando la ve después de un largo tiempo. Ella se sorprende: "iQué grande estás! ¡Que te fueron a cortar los rizos! ¡Eres todo un hombre!” $(1973,88)$.

El cuerpo tiene un lugar muy particular en el relato: se le va develando como fuente de placer, como obstáculo o como interrogante. Así, por ejemplo, un signo corporal común ocupa en la imaginación del niño el lugar primero del placer, y luego, de lo monstruoso: "En el baño solía cogerse las tetillas pequeñitas y rosadas, y reírse de ellas con la sirvienta. Esta le contaba cómo, a1 nacer, se le habían llenado de leche los primeros días; y Daniel, enmudeciendo, contemplaba muy serio sus pequeños pezones con cierto sentimiento de pavor $(1973,34)$. La materialidad del cuerpo fascina al protagonista, quien ya muchacho descubre allí una vocación: primero científica, luego literaria, en la medida en que aprende que "por una curiosa inversión de valores, el estudio de la materia lo llevaba a una región espiritual y yerta, sin aplicación ni proyección alguna sobre la buena vida ardiente de todos los días" (1973, 214), vida, ésta, a la que podrá acercarse a través del arte.

Por otra parte, en estas observaciones sobre el cuerpo es dable descubrir también la mirada de los otros - por ejemplo, la de la criada- que va configurando la subjetividad del pequeño Daniel. Se trata principalmente de voces femeninas, que irán marcando un "deber ser" de la identidad sexual. Así, por ejemplo, ante las preferencias poéticas del niño, la madre reacciona airada y le echa la culpa de estos gustos a otra mujer de la familia: "Los niños no tienen para qué aprender versos; los aburren y los excitan. Apostaría que son cosas de su tía", arguye la madre $(1973,49)$.

No es raro, pues, que los recuerdos de Daniel muestren la lucha de un ego que resiste ante el daño que producen las miradas de los otros. Los hombres, en su recuerdo y sin mediar explicaciones, aparecen pues "con el aspecto estúpido de los maniquíes en una tienda de provincia” $(1973,15)$, 
despojados de identidad, de caracteres que los hagan únicos, como una grey temible, en este caso también anodina o imbécil, como ocurre en otras muchas situaciones de la novela.

La sensibilidad del niño de lluvia debe desarrollarse en silencio y puertas adentro, en un mundo femenino gobernado por señoras y nanas, "mujeres autoritarias y erradamente espirituales" que demonizan todo lo referente al cuerpo, pero sobre todo, al varón: "Los hombres, decían las señoras, son sucios e inmorales por naturaleza" $(1973,38)$. En este mundo solo es admitido un cochero anciano, pero "puertas afuera", como un mal pensamiento (ibíd). Daniel ya ha tenido atisbos de la peligrosidad de los otros, encarnada en ese niño que lo ha increpado por no tener un padre. Pero se trata también de lo sucio y lo anómalo, de lo abyecto y lo extraño, en que se conjugan sexualidad y diferenciación social, todo aquello que debe ser alejado como un mal pensamiento. La imagen más clara de esta conjunción de sexo y clase se encuentra en el capítulo en que unos hombres "temibles y repugnantes" deambulan por el tercer patio de su casa (el de la servidumbre), "para recoger el cieno de la acequia" o, "no menos temidos y atrayentes", para desfilar "con grandes sacos al hombro dejando sembrado el camino de carbones y de la huella pavorosa de sus pies desnudos" $(1973,23)$. Daniel transgrede las barreras de la clase social y el pudor y se permite "un acto abominable":

Por esto, cuando años más tarde el instinto ciego comenzó calladamente su trabajo oculto, mucho antes de abrirse paso a la conciencia, al sexo o a lo que sea; cuando cierto escozor interno se engarza en todo lo que tiene sabor a veda, Daniel se permitió hacer un acto abominable: una mañana en que el panadero lo obsequió con una chocosa tibia y crujidora, él, agradecido, tendió tímidamente su mano blanca de niño que el otro estrechó con fuerza, ahogándola en su ancha mano negra de hombre del pueblo. Fue un instante de vértigo; luego corrió adentro, perseguido por una agradable culpabilidad, y fue tanta su turbación, que olvidó probar el enorme pan que apretaba nerviosamente bajo el brazo (23-24).

No es gratuita aquí la alusión al despuntar del sexo. El niño de lluvia se siente atraído por la oscuridad del hombre del pueblo, como ocurrirá luego también en otros pasajes del libro, entre ellos una escena que me llama particularmente la atención. Uno de los "allegados" del patio de servicio, de esos "demasiado morenos para encontrar acogida entre las sirvientas", o como describe otro pasaje "de esos, con chasca y todo, grueso el labio cubierto por un bozo 
sombrío y como rodeado el cuerpo por un halo ardiente que se desprendía de cada pliegue del pantalón" (82-83), aprovecha la ausencia de una de ellas en la cocina para "hablarle de esas cosas" al niño:

El muchachón, excitado, se acercó con cautela y poniéndose de rodillas junto a él: “ ‘mira!...” le dijo; y se descubrió rápidamente. Daniel miró de soslayo, con el gesto serio del que está meditando un grave problema; tomó el tiempo necesario para observar bien; luego, fingiendo un pudor exagerado, comenzó a gritar y a insultar al muchacho, amenazándolo con decirle todo a la mamá (las cursivas son mías, 35-36).

Entre la solicitud -"mira"- y la mirada -"de soslayo" que, sin embargo, se toma su tiempo para "observar bien"- hay algo elidido, sugerido por los puntos suspensivos: un cuerpo, un pene, probablemente una erección, ante lo cual Daniel finge "un pudor exagerado" (36). Claramente el cuerpo se oculta, así como también todas las manifestaciones sexuales o eróticas que se desvíen de las representaciones heterosexuales y saludables del patriarcado, como observa Molloy en literaturas fuertemente reprimidas. "Confesión y represión van unidas" (151), escribe el crítico Ramón García Castro del ensayo de Subercaseaux Santa Materia (1954), donde el autor haría explícita su fascinación por el cuerpo masculino. Algo similar ocurre en esta escena, en que se exagera el pudor, pero también se subraya el insulto. Aunque es menor, Daniel le grita al "muchachón", no solo porque exista una superioridad económica y social, sino también porque se pone en evidencia una marca propia de la formación masculina hegemónica, que rechaza con violencia cualquier acto que levante sospechas sobre su adecuada definición sexual. Sin embargo, Daniel no cumple con su amenaza de acusar al otro chico. La breve anécdota, aquello que se omite, se guarda como un secreto.

En este sentido, es legítimo vincular este pasaje con otros de Subercaseaux, quien le dio una particular importancia al niño no solo en esta novela, sino que también en su trabajo ensayístico. Ahí es posible encontrar algunas ideas de prosapia psicológica o antropológica, que van configurando un imaginario propio en torno a la experiencia infantil. Me interesa particularmente su defensa del ser humano "mutante", ser "mejor "terminado"” $(1972,378)$ que el "No-Mutante", esto es, en los términos evolutivos empleados por Subercaseaux, más "evolucionado". Desde su perspectiva este tipo de ser humano, durante su infancia, es discriminado e incomprendido: no es otra cosa que un "niño raro", introvertido $(1972,380)$. Este es, como veremos, el 
eje a partir del cual se estructuran las reflexiones de su novela, escrita varias décadas antes. Mientras en la novela se preocupaba de describir al "niño de sol", aquí el escritor está más atento a lo que otrora era el "niño de lluvia" y que en este texto es definido como "mutante":

Pero ocupémonos mejor de aquel niño que los psicólogos llaman: introvertido. Tal vez nos dará la clave de la infancia del Mutante. Aquel niño desde la edad de dos o tres años (a menudo antes) se muestra concentrado en sí mismo, no siempre alegre, algo torpe en sus manifestaciones motrices. Por eso, quizás, suele ser poco dado, después, a los juegos bullangueros y desordenados. El ama el orden... (381-382).

Lo más interesante de esta caracterización tiene que ver con los intereses naturalistas de este niño, intereses que aparecen en una suerte de continuidad con una observación acerca de la clase social:

Entre sus objetos preferidos están todos los productos de la naturaleza: flores, insectos, animales, piedras raras, sin que logren atraerlo mayormente los productos de la manufactura humana. (...) Más tarde, en la segunda infancia, cuando el prójimo pase a ocupar en su mente el lugar que corresponde al desarrollo del espíritu social del niño, su interés irá de preferencia hacia la gente del pueblo y no hacia los que pertenecen a su misma condición social. Si al niño Mutante del pueblo le ocurre la inversa y otro tanto, no lo hemos podido averiguar aún (382-383).

A cierta asimilación del pueblo con la naturaleza, del tipo civilización y barbarie, se suma la singular reflexión sobre la aproximación del niño mutante (varón y de clase alta, experiencia de la subjetividad que el psicólogo/ensayista parece conocer mejor que ninguna otra, diría yo que casi exclusivamente) a quienes no son de su condición social, experiencia que retrata más de una vez en su novela en situaciones de marcado (y secreto) homoerotismo.

\section{LA INFANCIA DEL EDIPO}

Kaja Silverman plantea que las relaciones de carácter homoerótico y/u homosexual se ven traspasadas por jerarquías y códigos sociales implícitos, las que constituyen una "ficción dominante" (cit. en Millington 35-36), esto 
es, la narración ejemplar de una subjetividad normativa de la sociedad. En nuestro continente, como sostiene Mike Millington, ésta dice relación con las ficciones del discurso nacional, las que socavan posibles ficciones individuales, equiparando al varón con "la autoridad y el control" (36) y negando de este modo las carencias reales de la identidad masculina. En el caso de los niños, quienes por su edad no han tenido posibilidad de ocupar un lugar en la esfera pública, no existe en ellos, aparentemente, agencia histórica ni poder alguno; se hallan confinados al hogar. Otros hombres y niños hacen recaer en ellos la sospecha (los llaman maricones, les exigen que muestren hombría) y/o el rechazo (en muchos casos, la violencia).

Eugenio, por su parte, circula a tientas por un libro que tuvo apenas una edición hace más de setenta años, si bien es, al menos en mi consideración, un relato que marca un antes y un después en la elaboración del punto de vista infantil en nuestro país, al intentar una narrativa subjetiva, asociativa, muchas veces onírica, en la línea inaugurada en Chile por autores como María Luisa Bombal, en 1935. El protagonista de La infancia es otro "niño de lluvia". La narración de su periplo se inaugura con una frase francamente proustiana: "Es un niño lleno de miedo, en la noche" (5), que en Los días ocultos aparece in media res, con una formulación menos absoluta: "Tiemblo de miedo, a medianoche" (16).

El protagonista de La infancia tiene cuatro años, se vincula de un modo especial con los objetos que lo rodean y registra como en escorzo las tensiones propias de la modernidad, particularmente a través de su observación crítica, desencantada, de una familia de clase media (el padre trabaja en una "oficina"), en que los progenitores viven su propio y silencioso infierno. Me parece que este aspecto es medular y por lo mismo hace insuficiente el certero análisis psicoanalítico emprendido por Roberto Hozven, en uno de los pocos textos críticos que existen sobre esta novela. Es insoslayable, a mi modo de ver, el diálogo que sostiene el texto con su contexto histórico: fue publicado bajo el gobierno del Frente Popular, en que el Estado tuvo un rol fundamental en la planificación económica y social del país y en el fortalecimiento de los sectores medios; bajo el lema "Pan, techo y abrigo" no podía sino fortalecer, también, a la institución familiar. Como en otras partes de América Latina, se identificó masculinidad con paternidad y femineidad con maternidad y se estigmatizó toda conducta que perturbara la relación conyugal "bajo la forma de patología o de crimen" (Figari 96), de los cuales había que preservar a la nación. En este sentido, me parece que es interesante escudriñar en el texto de Oyarzún sus críticas a la institución familiar, donde una madre 
joven, cristiana y melancólica, versión provinciana del ángel del hogar, vive el abandono de su marido. Las realidades del alcohol, la prostitución y el machismo son insinuadas desde la mirada del niño, que a su vez ama a la madre con una intensidad pocas veces vista en nuestra literatura, amor en el que insiste el libro posterior de este autor, Los días ocultos, pero desde una perspectiva menos intimista: bien observa Roberto Hozven que en tanto La infancia tiene como obertura la subjetividad afiebrada del niño, esta nueva narración (en primera persona) abre con una descripción de la Plaza de Armas del pueblo y va alternando de este modo las percepciones infantiles con una cartografía del pueblo, el paisaje, la casa, en que los elementos subjetivos han sido atenuados.

El niño se construye como un personaje marginal al interior de su propia familia, carente de información que le permita afincarse, hacer frente de algún modo a las amenazas que percibe alrededor. El relato insinúa permanentemente que existen secretos inalcanzables para su condición infantil, que lo fusiona permanente con un mundo de objetos demasiado próximos, asfixiantes: "Eugenio no puede dormirse sin sentir la presión de esta mano enguantada de las cosas" (5), que se reformula casi idénticamente en Los días ocultos: "No puedo dormir sin sentir esta presión enguantada de las cosas" (17), reiteración que a mi modo de ver subraya la importancia de esta línea narrativa para el autor. Solo a través de los objetos él logra relacionarse con el mundo de los padres, a quienes observa y admira a partir de sus ropas, sus joyas, sus muebles:

Su padre [...] deja la ropa en una silla negra. Eugenio ama la ropa de su padre. Es su mismo espíritu, pero sin enojos, sin palabras duras, tan bueno en el fondo. Y todo se refleja en la ropa: en la corbata dentro del cuello almidonado, silenciosamente suspendida. La camisa, blanca, dócil, los pantalones tienen algo de tiesura. Tal vez son un poco severos (9).

Los padres, a diferencia de los objetos, son inaccesibles: "Duerme con sus padres. Pero ellos ¡cuán lejanos! En un mundo seco, seguro, no en su humedad..." (5). La "humedad" de la que se habla aquí sugiere una relación viscosa, en gran medida una experiencia paralingüística, semiótica, fluida, del niño con el mundo. Como bien lo ha planteado Hozven, se trata de un niño que vive la fase fálica, encarnada en el deseo de fusión con la madre. La gran lucha que se libra en este relato, de hecho, es la que Eugenio da para poder mantener ese vínculo de proximidad con la madre: "se acuerda entre sueños de su madre, del lecho vecino de su madre y, lleno de miedo, 
navegando en una blanda materia desconocida, perdido en una ternura sin límites, se acuesta abrazado a su cuerpo, tan seguro, tan tibio, poderoso resplandeciente..." (6). Lejanía y cercanía resumen, pues, los afectos, los tropiezos, los movimientos tácticos del niño. En este sentido, ellos aparecen en una proximidad asombrosa, en tanto las figuras parentales se desvanecen y él intenta fijar un límite, acercarlos: "La alcoba permanece silenciosa, en un rincón la mamá teje, los hermanitos juegan sobre la alfombra, pero él está en estos momentos solo. Su límite lejanísimo es la madre, siempre a su lado aunque esté ausente" (20). Esta madre melancólica, bella, contagia a los objetos que son de su propiedad, los que se hallan todos bajo un mismo halo: " $\mathrm{AAh}$, los trajes de mamá son delicados, a la distancia se pueden sentir, tienen un aroma de lejanía que lo roza al dormirse!" (16); "La silla de su madre, igual a todas las demás, tiene un pálido tinte de lejanía que la diferencia..." (30).

Esta lejanía, que pienso "aurática", propia de los objetos artísticos cultuales (Benjamin), condiciona en el niño una relación con el mundo (y por ende, con la escritura) de carácter fetichista. Los objetos maternos estimulan el erotismo infantil, al punto que Eugenio desea, necesita "confesar", palabra religiosa e íntima, el amor que siente por su madre. Sin embargo, a lo largo del texto se sostiene la latencia de la confesión, de la palabra no dicha y ahogada por la presencia de un objeto distinto a todos los demás, objeto simbólico que proviene de otra esfera, el anillo de matrimonio vinculado con la ley paterna: "Cuánto le maravilla esa suavidad de sus manos, qué débiles parecen, y esa venita azul, y la argolla de matrimonio... Siente un desvanecimiento tibio. Entonces le dan ganas de dormir, siempre de la mano con su madre. Quiere tenerla a su lado" (16).

Se trata aquí del temprano despertar del niño y la adquisición de una conciencia adulta, al menos en lo que refiere al inevitable quiebre del vínculo con lo materno: la separación del niño y la madre es el Leitmotiv de esta narrativa, en que el padre aparece como figura protectora pero a la vez como amenaza, sombra proyectada sobre la madre y la relación materno-filial. El vínculo entre la madre y el padre se proyecta, metafóricamente, en el anillo, circunferencia de la unión, penetración del vacío en que se abisma el niño reiteradamente a lo largo del libro y que pareciera querer disolver, superar, ficcionalizando, poéticamente, el mundo que lo amenaza y lo asfixia.

Hozven concluye que, en la medida en que se resuelve el drama edípico, Eugenio finalmente descubre que la melancolía de su madre no es más que ficción: "Ella nunca perdió nada" (40), del mismo modo que su deseo de fusión fue un "gran espejismo" (40). Discrepo de la resolución que se da al relato 
sobre la madre en lo que respecta a las carencias de ese personaje, carencias que el narrador adulto de la historia señala y denuncia mostrando la realidad del hogar de clase media, como Nicomedes Guzmán formuló un modelo literario de hogar proletario en La sangre y la esperanza (los Quilodrán), mostrando al mismo tiempo sus contracaras (Alvarez 170-183). Es posible una lectura que trascienda el drama individual y refuerce las lecturas de aquel drama social al que Hozven también apunta en un momento de su análisis, que es el señalado por Gabriel Salazar y Sonia Montecino, entre otros: el drama del padre ausente, la fractura que se instala en los orígenes de la sociedad chilena. La lectura de Los días ocultos, novela más estructurada y con un título que significativamente apunta a esa dimensión de la experiencia que la infancia apenas intuye -su formulación más clara está en el relato de una de las pesadillas del narrador: "bajamos a un país de nieve en que todo es engaño y ocultamiento. Todo se oculta. Todos se han ocultado de mí" (21)-y en que se regula más la relación con la madre (ya no aparece la viscosidad objetual, la verdadera fiebre que inunda el planteamiento de La infancia), esclareciéndose la relación con el mundo exterior del pueblo de provincia y sus instituciones, en una lectura que permite visualizar con más claridad las críticas al orden político (y la micropolítica) en su relación con la familia.

\section{LA INFANCIA DEL ENFERMO}

Daniel, Eugenio y Santiago son niños de la burguesía chilena, llamados a competir con otros varones para ocupar cargos de importancia. Por su condición de clase parecen moldeables a través de la educación y, como dice Carlos Figari, de "los dispositivos del hábito y del remordimiento", esto es, del autodisciplinamiento (110) y el higienismo, que en Chile se fortalece a partir de 1925, evitando, mediante la actividad física, hábitos considerados perniciosos, como la masturbación. Con ese mismo fin, sostiene Figari, toda la administración del tiempo se supeditó al afán normativo que regulaba no solo el ejercicio, sino también la lectura, cuyo exceso o inconveniencia podía predisponer a la excitación sexual (Figari 111).

Si miramos a los pequeños protagonistas de estas historias, veremos hasta qué punto ellos se desmarcan de estos disciplinamientos. Como ya he planteado, se trata de niños débiles, poco sociables, enfermizos. Hacia 1905, en que ya se habla del problema de la alta tasa de mortalidad infantil, Daniel habita un espacio urbano insalubre y peligroso para los niños. "Los niños mimados 
eran mantenidos en un enclaustramiento irritante como un secuestro" (37), explica el narrador. La enfermedad - a la que Oyarzún le dedica en Los días ocultos los capítulos "Enfermedades" y "Convalescencia"- trae el encierro y largas estadías en cama, lugar en que es posible, dentro del hogar burgués, emprender conocimiento del cuerpo y burlar la vigilancia doméstica, además de desarrollar sus lecturas y con ello transgredir los códigos que les impone su represiva rutina.

Las experiencias descritas irán delineando el carácter del protagonista, quien además de ser un niño distinto a aquellos "de sol" por su conducta retraída y sensible, se revela como alguien distinto por su calidad de "extranjero", "gringo", proveniente de una cultura distinta, la cultura francesa que le viene por herencia paterna, herencia que también aparece en Wacquez y su personaje, Santiago de Warni.

Como en ninguna de las otras novelas hasta ahora analizadas, emerge aquí el problema de los contextos formativos y disciplinarios a los que se vieron sometidos los niños varones de clase alta en Chile entre 1905 y 1950, período en que se desarrollan sus infancias y en que el Estado, como ocurrió también en otros países latinoamericanos, buscó instaurar un ideario patriótico. Para ello, "toda afección o comportamiento que pudiera perturbar la debida relación conyugal", afirma Carlos Figari, era "patología" o "crimen" (96). Las transgresiones sexuales eran disidentes no solo de la normatividad hegemónica de género, sino también de una voluntad articuladora más amplia de la realidad nacional. Lucía Guerra plantea que en nuestros países es posible hallar, cito, una "cartografía genérica que oscila entre lo regimentado y la resistencia transgresora", que se opone a la "exaltación de una modalidad violenta de la masculinidad" y los "parámetros heteronormativos" que rigieron la vida social en la primera mitad del siglo, cartografía en la que me parece podrían inscribirse estos relatos, que muestran cómo los valores fundantes de la oligarquía chilena, católica y de raigambre colonial, se ven transgredidos en el seno mismo de la institución familiar por provocativos vástagos de la oligarquía, quienes debían de estar llamados, por su clase, a dominar la política nacional.

Enfermedad y violencia son dos ejes en torno a los cuales se articula la epifanía de Santiago de Warni, quien pasa en cama dos largos períodos de su vida, aquejado primero de una meningitis y luego, de una afección cardíaca. Esta infancia verdaderamente proustiana es la primera parte de una trilogía autobiográfica que Mauricio Wacquez, alejado por décadas de Chile, pensaba llamar La oscuridad. La estructura de esta primera parte, en 
que presenta los primeros veinte años de Santiago de Warni, es difícil: está dividida en numerosos apartados temáticos, sin numeración, subtítulos ni orden cronológico, donde se alternan narradores en tercera y primera persona y tiempos diversos (algunos refieren a la niñez, otros a la juventud, otros, al tiempo de la enunciación), conformando lo que Brian Dendle ha llamado "una onda expansiva de una complejidad cada vez mayor". Son los hallazgos del cuerpo, el sexo, el intelecto, la clase social y el poder los núcleos desde los cuales, a mi juicio, se expandería esta narrativa, que, escrita con posterioridad a los años de la liberación sexual y el sida, ya no requiere ocultar, como ocurre en varios de los pasajes escritos por Benjamín Subercaseaux, sino que, por el contrario, busca nombrar la heterosexualidad, la homosexualidad, las numerosas formas de acoplamiento de los cuerpos.

Uno de los hechos más significativos de esta novela es el morboso asesinato del Chino Olavarrieta, compañero de colegio de Santiago, primer amor de adolescencia y miembro de una familia acaudalada a la que, sin embargo, "se le nota un poco la ojota", con quien el protagonista vive apenas un torpe, rápido encuentro en la estrecha cabina de una avioneta. Cito: "le había dado un puyazo al blando rabel de Vicente. Éste no se dio por aludido. Sin embargo, Santiago creyó que, en aquel momento, su víctima había disfrutado y que el chuzo, la matraca, la penca, el rabo, el rebenque, la clava, la tranca, la cachiporra, la comba, el nabo, el tallo, la porra, el vergajo eran para Vicente denominaciones de una misma delicia" (187). Simbólicamente, en un complejo juego de ausencias y presencias, el narrador plantea que el Chino o Vicho, galán adolescente del que se presumen intolerables proezas sexuales, es hallado muerto, con el miembro viril emasculado, en los alrededores de la casa patronal.

Como plantea Rubí Carreño, refiriéndose a Marcuse y Reich, "el erotismo no es un valor cultural" y es por eso que suele ser castigado; en este sentido, la escritura de Wacquez muestra sucesivos castigos pero al mismo tiempo se constituye en sí misma placer erótico, "una instancia-cito a Carreño-que desafía los castigos y se erige en sí misma como goce (de decir lo que no se dice) y como placer (decirlo a través de un artefacto cultural de prestigio)" (32). Es interesante lo que ocurre en el enciclopédico texto de Wacquez, en donde la botánica, la geografía, la filosofía, el mito y la historia, pero también las novelitas pornográficas decimonónicas concurren a la narración epifánica sobre un niño que, al despertar de una larga inconsciencia, experimenta el despunte del deseo sexual y sus permanentes desplazamientos, su inagotabilidad, su irracionalidad que es también muerte e insólita afirmación del bios: 
todo tiene un comienzo, todo tiene un final. Ante ese límite, el lenguaje es afirmación, proliferación, derroche, pérdida. Nada es elidido, por el contrario: el significante fálico evoca la vitalidad y también la oscuridad: es todo. A diferencia de Subercaseaux, que plantea una dicotomía - niños de lluvia versus niños de sol y en el pasaje que dedica al colegio, niños buenos versus niños degenerados- en el universo narrativo de Wacquez aquello realmente profundo, que es la violencia y el deseo, se define como una mezcla de luz y oscuridad, una sombra que imprime su huella sobre todas las cosas. No hay separación, como ocurre desde el mismo título de la novela: una epifanía, que es un reconocimiento, el hacerse una luz, es epifanía de sombra que se produce después de una larga enfermedad que conecta a Santiago con la muerte. Cito nuevamente: "no es la luz, como propone la teología, el agente penetrante, la agudeza, el contorno, la idea, la inteligencia, sino el vasto tremedal donde florece la rosa fétida, donde todo está analizado, desmontado en suntuosos contrarios, en estados de ánimos, en conjeturas absurdas y animales execrables" (63). El mundo en su descomposición, el tramado barroco de plantas y árboles, de animales y humanos que se trenzan en estas páginas es lo que Wacquez procura poner de relieve. En este universo en que no existe la luz que como un cuchillo corta y separa el mal del bien, lo bello de lo espantoso, lo real de lo ficcional, sino un todo de sombras indiferenciadas, llama la atención que el significante fálico asome en un mito con que el narrador apuntala sus planteamientos estéticos y políticos. Wacquez recoge ni más ni menos que la figura de Príapo, el empalmado, "víctima", cito, "de la claridad de ser hermano gemelo de Apolo, ¡desterrado!, aherrojado a ser dios de los huertos", el pobre Príapo "cuya deformidad" atenta "contra los principios dictados por un empíreo cruel”. “Por qué había de plegarse a las severas normas de lo racional cuando la oscuridad es una instancia mucho más intensa clavada en el corazón del deseo? ¿Y por qué no entonces dirimir la alternativa eligiendo las proposiciones del mal, una especie de liturgia que englobara a todos los descontentos de la belleza, del amor, de la luz?" (236), se pregunta el narrador.

Quisiera concluir, proyectando nuevamente los paralelismos, principalmente entre la novela de Subercaseaux y la de Wacquez, una profunda divergencia entre ambos. En tanto el sensible niño de lluvia de Subercaseaux se resiente en numerosos pasajes del texto por la falta de belleza del estrecho mundo colonial en que se desarrolla su imaginación, cercado por sirvientas viejas y feas y por matriarcas vetustas, el sensible monstruo que es Santiago no desea la belleza. En su mundo no prima la razón analítica que divide a los 
violentos de las víctimas ni a los malos de los buenos. El sexo, el cuerpo y el falo (significante del poder) se expanden y proyectan violenta, verbalmente. El mundo de casas de tres patios, severos colegios religiosos y costumbres coloniales que muestra Wacquez es, pues, tan solo externamente parecido al de Daniel: otra dinámica hay en su lenguaje, ese lenguaje que busca nombrar, renombrar, no ocultar. Entre los textos de esa verdadera genealogía de la hacienda que hay en la literatura chilena, su novela resulta fundamentalmente significativa: híbrida, emblemática, plegada. Insoslayable desde un punto de vista crítico.

Tanto Eugenio como el narrador en primera persona de Los días ocultos, como Daniel y Santiago son, pues, pequeños adalides de la estética que proponen visiones alternativas a la formación de la masculinidad por parte de la pedagogía y el higienismo propios de la primera mitad del siglo XX. Relegados al dormitorio, enfermos, melancólicos, estos niños se sitúan en un lugar privilegiado para criticar la uniformidad del maniquí de provincia que es, finalmente, el macho hegemónico del ideario nacional.

\section{BIBLIOGRAFÍA}

Álvarez, Ignacio. Novela y nación en el siglo XX chileno. Ficción literaria e identidad. Santiago de Chile: Ediciones Universidad Alberto Hurtado, 2009. Impreso.

Amaro, Lorena. "La reescritura de 'La infancia' en 'Los días ocultos', de Luis Oyarzún”. Revista Aisthesis n54, dic. (2013): 303-318. Impreso.

Amaro, Lorena y GhislaineArecheta. "Modernización y experiencias de infancia en la narrativa chilena de la primera mitad del siglo XX". Confluencia, Volume 29 №2 (Spring 2014), en prensa.

Balderston, Daniel. El deseo, enorme cicatriz luminosa. Ensayos sobre homosexualidades latinoamericanas. Rosario: Beatriz Viterbo, 2004. Impreso.

Balderston, Daniel y José Quiroga. Sexualidades en disputa. Homosexualidades, literatura y medios de comunicación en América Latina. Buenos Aires: Universidad de Buenos Aires, 2005. Impreso.

Carreño, Rubí. "El huaso y la lavandera: significaciones de la sexualidad y la violencia en la construcción de géneros en la narrativa chilena”. En Olavarría, José y E. Moletto. Hombres: Identidad/es y Sexualidad/es. Santiago: FLACSO, 2002, 29-36. Impreso.

Leche amarga. Violencia y erotismo en la narrativa chilena del siglo XX (Bombal, Brunet, Donoso, Eltit). Santiago: Cuarto Propio, 2007. Impreso.

Dendle, Brian. "La última novela de Mauricio Wacquez: Epifanía de una sombra”. Revista Chilena de Literatura $\mathrm{n}^{\circ} 60$ (2002): 87-99. Impreso. 
Figari, Carlos. Eróticas de la disidencia en América Latina: Brasil, siglos XVII al XX. Buenos Aires: CICCUS, 2009. Impreso.

García Castro, Ramón. "El cuerpo masculino visto por ojos latinoamericanos: Santa materia (1954) de Benjamín Subercaseaux y 'Vida ejemplar del esclavo y el señor' (1983) de Manuel Ramos Otero”. Revista Iberoamericana, Vol. LXII, N 174 (Enero-Marzo 1996): 149-161. Impreso.

Guerra, Lucía. "Tramas del poder en las interrelaciones de género y espacio". En Salomone, Alicia, Lorena Amaro y Ángela Pérez (Eds.). Caminos y desvios: lecturas críticas sobre género y escritura en América Latina. Santiago de Chile: Cuarto Propio, 2010, 37-52.

Hozven, Roberto. Escritura de alta tensión. Desafio de Luis Oyarzún. Santiago de Chile: Catalonia, 2010. Impreso.

Millington, Mark. Hombres in/visibles. La representación de la masculinidad en la ficción latinoamericana, 1920-1980. México: FCE, 2007. Impreso.

Oyarzún, Luis. La infancia. Santiago de Chile. Ediciones Revista Nueva, 1940. Impreso. Los días ocultos. Santiago: Pacífico, 1955. Impreso.

Rojas Flores, Jorge. Historia de la infancia en el Chile Republicano. 1810-2010. Santiago de Chile: Ocholibros, 2010. Impreso.

Schoene-Harwood, Berthold. Writing Men: Literary Masculinities from Frankenstein to the New Man. Edinburgh: Edinburgh University Press, 2000. Impreso.

Subercaseaux, Benjamín. Daniel, niño de lluvia. Santiago de Chile: Ercilla, 1942.

Niño de lluvia. Santiago de Chile: Zigzag, 1973. Impreso.

Una nueva interpretación del hombre (Teoría de la Desnaturación Antropológica). Santiago de Chile: Andrés Bello, 1972. Impreso.

Valdés, Hernán. Fantasmas literarios. Una convocación. Santiago de Chile: Aguilar, 2005. Impreso.

Wacquez, Mauricio. Epifanía de una sombra. Santiago: Sudamericana, 2001. Impreso. 